\title{
Comparative Study of Real and Virtual Garments Appearance and Distance Ease
}

\author{
Agnė LAGE் 1 *, Kristina ANCUTIENE் ${ }^{1}$, Rūta PUKIENE் ${ }^{1}$, Eva LAPKOVSKA ${ }^{\text {, }}$ \\ Inga DĀBOLIN̦A ${ }^{2}$
}

\author{
${ }^{1}$ Faculty of Mechanical Engineering and Design, Department of Production Engineering, Kaunas University of \\ Technology, Studentu st. 56, LT-51424 Kaunas, Lithuania \\ ${ }^{2}$ Faculty of Material Science and Applied Chemistry, Institute of Design Technologies, Riga Technical University, \\ Kipsalas st. 6, LV-1048 Riga, Latvia
}

crossref http://dx.doi.org/10.5755/j01.ms.26.2.22162

Received 28 November 2018; accepted 27 January 2019

\begin{abstract}
Nowadays, virtual try-on is an irreplaceable technology in fashion industry, so it is very important to prove virtual try-on matching with the real garments. Therefore, the aim of this research was to compare garment fit using virtual try-on and scanning technologies. For this reason, garment visual appearance and distance ease between straight fit dress and mannequin in respect to fabrics properties were investigated. Women mannequins in different sizes were scanned by 3D scanner VITUS Smart XXL without and with the real straight fit dresses made from five different woven fabrics. Fabrics mechanical properties were defined by KES-F. Scanned mannequins were covered with the same size and fabric virtual dresses by Modaris 3D (CAD Lectra). Distance ease of virtual and scanned garments was compared in bust and waist cross-sections. It was defined that distance ease values at bust girth of real and virtual dresses differed till $29.9 \%$ $(1.16 \mathrm{~cm})$, while at waist varied from $7.3 \%(0.51 \mathrm{~cm})$ to $47.3 \%(4.30 \mathrm{~cm})$ because of wrinkles in this area. Generally, appearance of the virtual dresses was similar to real dresses with some differences in garment shape fluency, however by increasing of the mannequin size, similarities decreased. It was assumed that very high shear rigidity $G$ could not be very well reflected in 3D CAD system, therefore differences between virtual and real dresses appearance occurred. The general appearance and form of bust and waist cross-sections of virtual dresses with fabric 03 had less similarities comparing with real dresses due to high $G$ value. So, comparative study showed that the accuracy of virtual try-on was quite useful comparing to real garments, if shear rigidity of fabrics was lower than $1.6 \mathrm{Nm}^{-1} f^{\circ}$ and tensile strain in warp direction was higher than $1.80 \%$.

Keywords: 3D body scanning, fabric simulation, garment appearance, virtual try-on, distance ease.
\end{abstract}

\section{INTRODUCTION}

Today's industry is experiencing the 4th industrial revolution of textiles and clothing, in which particular attention is paid to digitization and virtualization. This process is implemented on the basis of the most important research priorities - virtual modelling and design of fibres, fabrics and garments. Therefore, in the past decade, 3D body scanning systems and 3D CAD systems with virtual try-on software gained considerable attention.

Virtual prototyping with virtual try-on software provides significant benefits to the apparel manufacturers [1]. It helps to minimize physical samples for each garment before production, ensures accuracy, flexibility, time saving and suggests well-fitted garment for individual body type [2-5]. Virtual prototyping of 3D garments represents not only fit to body, what is the main purpose, but also garment pattern design, style, colours, virtual human body and mechanical properties of fabrics [6-8]. $3 \mathrm{D}$ virtual prototyping process includes the following steps: determination of fabric properties, preparation of virtual mannequin and garment pattern for simulation, virtual sewing, virtual garment try-on, evaluation of the virtual garment fit and appearance on the virtual mannequin [6].

\footnotetext{
* Corresponding author. Tel.: +370-37-300237; fax: +370-37-323461.

E-mail address: agne.lage@ktu.edu (A. Lage)
}

3D CAD systems are used for 2D apparel pattern assembly and draping on 3D virtual mannequins for prototyping of garments, virtual fitting sessions and fabric behaviour imitation. Today the majority of apparel CAD software provides 3D virtual try-on modules, such as Clo 3D by CLO, Modaris 3D Fit by Lectra, V-StitcherTM by Browzwear, i-designer by Technoa, Tuka3DTM by Tukatech, Haute Couture 3D by PAD system, Vidya by AssystBullmer, Qualoth, Narcis by D\&MFT and others $[2,9,10,11]$.

Virtual mannequin preparation is one of the most important parts of garment virtual try-on process. In order to get the best result of garment fit to the human body, precise anthropometric data are necessary. The virtual human body mannequin based on 3D anthropometry can be created by two methods: 1) the manual avatar, using body measurement; 2) the direct avatar, using 3D body scan form [8]. 3D body scanning is a relatively new method [12]. By the advanced 3D scanning techniques, the individual human body can be easily captured [13].

Many researchers compared the real garment appearance on the human body with the 3D virtual garment appearance on the virtual mannequin using 3D scanning and 3D CAD systems and evaluated garment fit taking into account the structural and mechanical parameters of the fabrics $[2,7,14,15]$. There are mainly two methods to evaluate garment fit and comfortability through virtual tryon. First of them is visual assessment of 3D garment fit 
when pressure, stress and fit maps are generated by virtual try-on software $[8,14]$. Second method is to measure the ease allowances in the selected girths or air layer thickness between the garment and the human body [9]. J. Q. Yan et al. [5] used virtual database for designing garments. It was called "dress-body" system. In order to analyse garment fit, some parameters (bottom height of dress, angle of front center contours, air volume and its distribution between dress and mannequin) were related with fabrics mechanical properties and pattern block indexes, to improve construction, fit and appearance. V. Kuzmicev and M. Guo [16] improved "body-dress" system using the 3D body scanning. They divided torso of scanned dresses into 6 sections from bust to hip level, calculated the volumetric air gaps between the body and dress and analysed relationships between the body sizes, pattern block indexes and fabric properties. They determined that bending stiffness $B$ was the contributing factor in the upper part and bottom bearing surface part of dress, while tensile ability became the causative factor for the part between upper and bottom surfaces. J. Su et al. [17] showed a way to solve the problem of garment ease distribution using 3D scanning data of a clothed and unclothed body. The scanned surfaces were divided in selected cross sections for pants ease determination; the air gap between the cross-sections at each section was measured. The results showed that when the ease allowance is given, the distance ease can be calculated by regression equations. B. Gu et al. [18] used similar method for jacket ease determination. J. Xu et al. [19] calculated the distance ease - the shortest distance from the body curve to the garment curve in cross-sections of scanned clothed and unclothed mannequin.

Researchers try to combine 3D scanning and virtual try-on technology together in order to design the best fit of garment. For effective practical use of virtual try-on, it needs to be investigating how practically garment fit is simulated by the particular technology and whether there is a gap between the real and virtual garment [20]. However, the most of the scientists focuses into comparing the garment fit of real and virtual body model with parametric mannequin using 3D CAD system. There is another approach for evaluating garment fit to use the actual scanned 3D body model [7].

H. K. Song and S. P. Ashdown [2] investigated whether 3D virtual try-on technology can effectively visualize the fit and silhouette of pants. Results showed that the accuracy of virtual try-on is quite useful, especially for pants with good fit, but not to the extent that experts could fully use it as a visual fit analysis tool. E. Buyukaslan et al. [15] evaluated fit differences from images of a skirt on a real body, scanned and parametric body models. They concluded that the scanned and the parametric model especially differs at waist and hips areas. Due to undefined waist line in scanned model and fabric mechanical properties, for visual difference might be that the fabric softness is not very well reflected in computer program. J. Lee and J. Lee [22] compared the pants fit for obese women using 3D virtual and real garment. They stated, that 3D virtual garment simulation was reliable, because there was no significant difference in appearance caused by materials between real and virtual garment. The ease of virtual and real garment was similar.

Virtual try-on and 3D body scanning technologies are efficient, convenience and valuable tools for visual fit analysis $[2,5]$. It is very important to prove virtual try-on matching with the real garments therefore, the aim of this research was to compare distance ease between mannequin and the garment, also appearance of a real and virtual garments, using virtual try-on and scanning technologies.

\section{EXPERIMENTAL DETAILS}

In this research, 2D patterns of the straight fit dress (Fig. 1) were constructed for standard size (170-92-100) with $5 \mathrm{~cm}$ ease allowance by Modaris (CAD Lectra) software. The basic block patterns were created according to M. Müller and Sohn patternmaking system [23] and were modified after initial virtual try-on to take account of defects caused [24]. The bust girth of the mannequin passes through the highest points of the bust, while the waist girth is at the narrowest part of the waist. Bust and waist girths on the garment correspond bust and waist lines in the $2 \mathrm{D}$ basic block pattern.

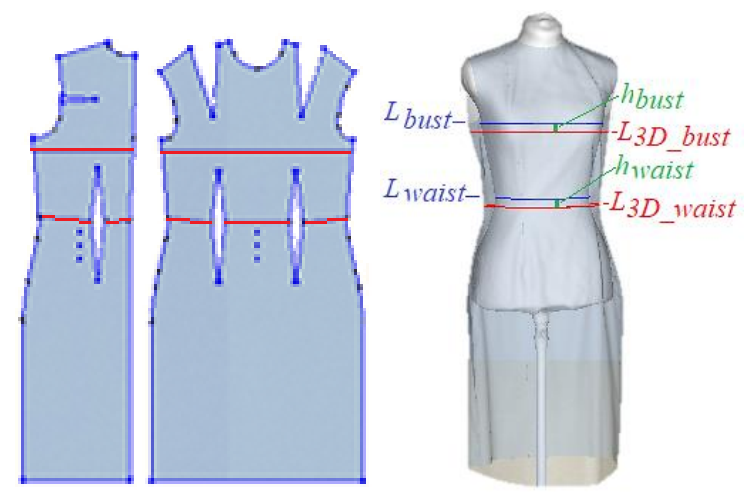

Fig. 1. 2D dress patterns and 3D dress with marked bust and waist girths on garment (red color) and mannequin (blue color), also mismatches between girths (green color)

The garment fitting was done using five cotton/elastane blended woven fabrics. The main mechanical characteristics of fabrics in warp (wp) and weft (wf) directions were defined by KES-F (Kawabata Evaluation System for Fabrics) using standard conditions (Table 1).

Scanning process started with the mannequin preparation: initial women mannequin was covered by stretchy fabric to hide the regulators (Fig. $2 \mathrm{a}$ and b). Size of the mannequin was changed uniformly from 88 to $95 \mathrm{~cm}$; step was $1 \mathrm{~cm}$. At first mannequin was scanned by 3D scanner VITUS Smart XXL without dress (Fig. $2 \mathrm{~b}$ and d). Later, the mannequin was scanned with the real dresses made from five different woven fabrics (Fig. $2 \mathrm{c}$ and e). There were 48 scans performed in total. The views of scanned unclothed and clothed mannequins are presented in Anthroscan software (Fig. $2 \mathrm{~d}$ and e).

Scanned unclothed mannequins were imported into Modaris 3D software (CAD Lectra) to make virtual try-on (Fig. $2 \mathrm{f}$ ) and to compare with the scanned ones. Each real and virtual dress was tested at bust and waist cross-sections (Fig. 3). 
Table 1. Structural and mechanical characteristics of tested fabrics

\begin{tabular}{|c|c|c|c|c|c|c|c|c|c|}
\hline \multirow{2}{*}{ Code } & \multirow{2}{*}{ Composition } & \multirow{2}{*}{$\begin{array}{c}\text { Thickness, } \\
\text { mm }\end{array}$} & \multirow{2}{*}{$\begin{array}{c}\text { Mass per } \\
\text { unit area, } \\
\mathrm{g} / \mathrm{m}^{2}\end{array}$} & \multicolumn{2}{|c|}{$\begin{array}{c}\text { Tensile strain } \\
E M T, \%\end{array}$} & \multirow{2}{*}{\multicolumn{2}{|c|}{$\begin{array}{c}\text { Bending rigidity } \\
B, 10^{-6} \mathrm{Nm}\end{array}$}} & \multirow{2}{*}{\multicolumn{2}{|c|}{$\begin{array}{c}\text { Shear rigidity } \\
\qquad G, \mathrm{Nm}^{-1} \rho^{\circ}\end{array}$}} \\
\hline & & & & wp & wf & & & & \\
\hline 02 & $98 \%$ cotton, $2 \%$ elastane & 0.567 & 205 & 11.77 & 19.70 & 5.26 & 2.93 & 0.87 & 0.64 \\
\hline 03 & $97 \%$ cotton, $3 \%$ elastane & 0.423 & 130 & 4.28 & 27.90 & 8.99 & 3.09 & 1.69 & 1.66 \\
\hline 04 & $96 \%$ cotton, $4 \%$ elastane & 0.397 & 110 & 1.78 & 29.03 & 11.08 & 2.29 & 1.24 & 0.89 \\
\hline 05 & $95 \%$ cotton, $5 \%$ elastane & 0.270 & 90 & 6.37 & 31.63 & 4.82 & 1.47 & 1.11 & 0.96 \\
\hline 06 & $93 \%$ cotton, $7 \%$ elastane & 0.577 & 215 & 3.53 & 33.30 & 15.14 & 7.19 & 1.33 & 0.98 \\
\hline
\end{tabular}

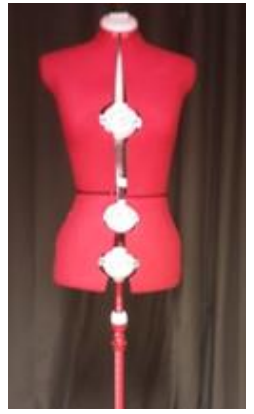

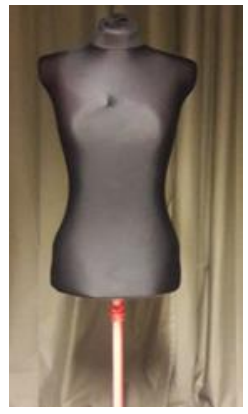

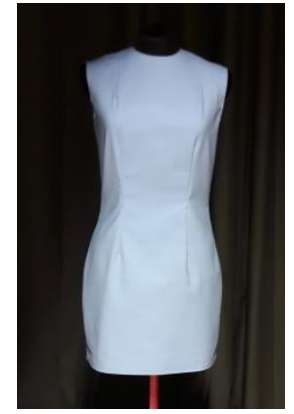

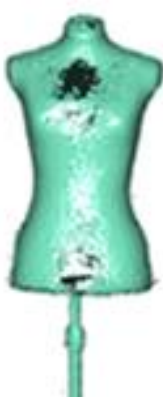

d

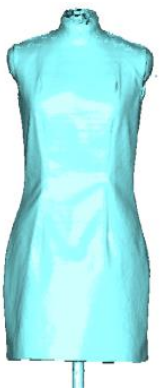

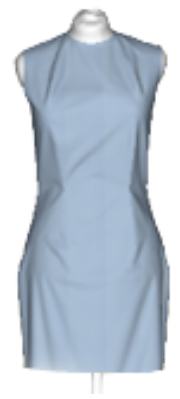

f

Fig. 2. Methodology sequence: $a$-initial mannequin; $b$-mannequin with cover; $c$-mannequin with the real dress; $d$-scanned unclothed mannequin; $\mathrm{e}$-scanned mannequin with real dress; $\mathrm{f}$ - scanned mannequin with virtual dress

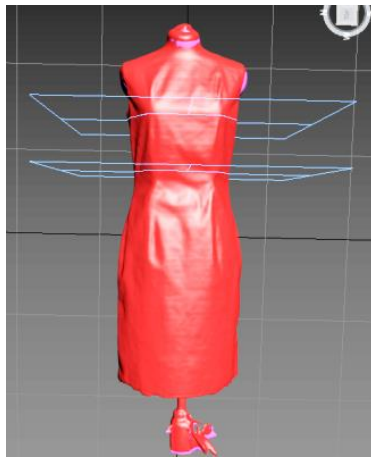

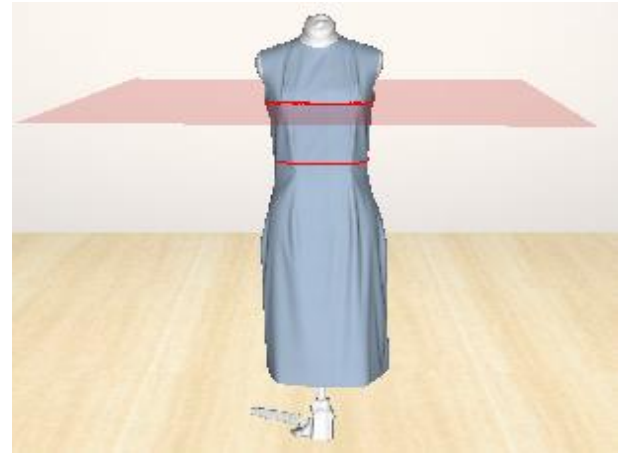

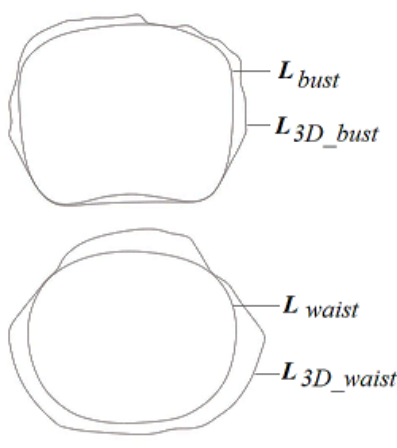

Fig. 3. Preparation of cross-sections: $a-$ planes of cross-sections in real scanned dress (3D Max); b-planes of cross-sections in virtual dress (Modaris); $\mathrm{c}$ - view of bust and waist cross-sections

3D distance ease $\left(E S_{3 D \_b u s t, w a i s t}, \mathrm{~cm}\right)$ between body and a garment at bust and waist cross-sections of real and virtual dresses were investigated by 3Ds Max and AutoCAD software packages. Scanned unclothed and clothed mannequins in appropriate size were imported into 3Ds Max software; the subjects were matched with each other and then sliced by planes at bust and waist girths. Distance ease of virtual garment was estimated in Modaris 3D software using measuring tool. 3D distance ease was calculated according to Eq. 1 [24].

$$
E S_{3 D_{-} \text {bust,waist }}=L_{3 D_{-} \text {bust,waist }}-L_{\text {bust,waist }} \text {; }
$$

where $L_{3 D_{-} \text {bust,waist, }} \mathrm{cm}$ (Fig. $3 \mathrm{c}$ ) is the perimeter of $3 \mathrm{D}$ garment at correspondent cross-section, it was measured by AutoCAD for real dress $\left(L_{3 D R_{-} \text {bust,waist }}\right)$ and by Modaris $3 \mathrm{D}$ for virtual dress $\left(L_{3 D V \_b u s t, w a i s t}\right) ; L_{\text {bust, waist, }} \mathrm{cm}$ is the length of perimeter of mannequin at correspond cross-section. Mismatch $h$ (Fig. 1) between $L_{\text {bust,waist }}$ and $L_{3 D_{-} \text {bust,waist }}$ measure lines were evaluated of real and virtual dresses.
Virtual try-on of each virtual dress was done three times and then measurement of 3D distance ease values at bust and waist girths was taken and quotient of variation $v$ was calculated. The quotient of variation did not exceed $10 \%$.

Real dresses were scanned once using scanning equipment which is compatible with ISO 20685 (3-D scanning methodologies for internationally compatible anthropometric databases - Part 1: Evaluation protocol for body dimensions extracted from 3-D body scans). There are stated maximum error between extracted value and traditionally measured value, which is $9 \mathrm{~mm}$ for large circumferences (e.g. bust circumference) and $4 \mathrm{~mm}$ for small circumferences (e.g. neck circumference). This is called as the systematic measurement error which will be the same for all scans in the same equipment therefore can be declared as statistically indifferent. Theoretically calculated quotient of variation of scanned objects did not exceed $0.7 \%$. 


\section{RESULTS AND DISCUSION}

It was defined that differences between the length of real and virtual dresses perimeter lines at bust girth $L_{3 D_{-} \text {bust }}$ varied from $0.1 \%$ to $3.4 \%$ and from $0.1 \%$ to $4.9 \%$ at waist girth $L_{3 D_{-} \text {waist }}$. However, 3D distance ease values had higher differences comparing virtual and real garments.

Distance ease values at bust girth of real and virtual dresses differed up to $29.9 \%(1.16 \mathrm{~cm})$, except fabric 03 in all sizes (Table 2). The difference of $E S_{3 D \_b u s t}$ using fabric 03 varied from $12.3 \%(1.04 \mathrm{~cm})$ to $48.3 \%(1.46 \mathrm{~cm})$.

Virtual dresses had higher distance ease values than real dresses with all tested fabrics (except fabric 03) in almost all sizes (Table 2). Virtual dresses with fabric 03 showed the biggest differences; it had $E S_{3 D_{-} \text {bust }}$ values from $12.3 \%$ to $48.3 \%$ lower than real dresses for all mannequin sizes. These dresses occurred with wrinkles in bust area because of the highest shear rigidity $G$ (Table 1) what might be not simulated precisely and caused differences comparing with other fabrics. The lowest differences of distance ease in all sizes showed fabric 05 (Table 2).

Linear relations of real (Fig. 4) and virtual (Fig. 5) dresses between mannequin size and 3D distance ease values at bust girth showed, that the highest distance ease of real dresses was formed with fabric 03 and 06 , and the lowest with fabrics 02 and 04 . While the highest distance ease of virtual dresses was formed with fabric 06. However virtual dresses in different sizes with different fabrics did not have a clear tendency that could be seen in the real dresses.

The difference of distance ease between real and virtual dresses at waist girth $E S_{3 D_{-} \text {waist }}$ varied from $7.3 \%$ $(0.51 \mathrm{~cm})$ to $43.3 \%(3.21 \mathrm{~cm})$, except fabric 03 in all sizes (Table 3). The difference $E S_{3 D_{-} \text {waist }}$ of fabric 03 varied from
$31.2 \%(4.08 \mathrm{~cm})$ to $47.3 \%(4.30 \mathrm{~cm})$. This could be explained due to the wrinkles occurred at waist area, because garment had not enough distance ease at hip, therefore it stacked and wrinkles at waist originated [24]. Real dresses had higher $E S_{3 D_{-} \text {waist }}$ values than virtual dresses in all cases. The highest difference between real and virtual dresses $E S_{3 D_{-} \text {waist }}$ was observed with fabric 03 -from $31.2 \%$ to $47.3 \%$, while fabric 04 had the best match (Table 3).

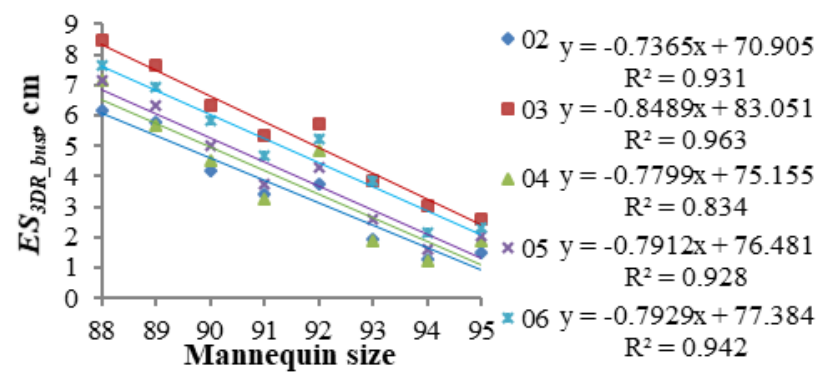

Fig. 4. Linear relations between mannequin size and 3D distance ease of real dress at bust girth

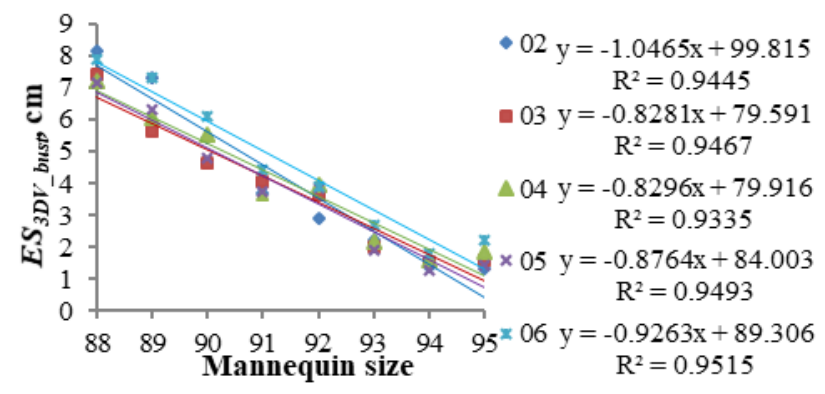

Fig. 5. Linear relations between mannequin size and 3D distance ease of virtual dress at bust girth

Table 2. 3D distance ease $E S_{3 D \_b u s t}$ values at bust girth: $\mathrm{R}$-real dress, $\mathrm{V}$ - virtual dress (the best coincidence in each size are marked in bold, while the biggest differences - in Italic)

\begin{tabular}{|c|c|c|c|c|c|c|c|c|c|c|}
\hline \multirow{2}{*}{ Size/Fabric } & \multicolumn{2}{|c|}{02} & \multicolumn{2}{|c|}{03} & \multicolumn{2}{|c|}{04} & \multicolumn{2}{|c|}{05} & \multicolumn{2}{c|}{06} \\
\cline { 2 - 12 } & $\mathrm{R}$ & $\mathrm{V}$ & $\mathrm{R}$ & $\mathrm{V}$ & $\mathrm{R}$ & $\mathrm{V}$ & $\mathrm{R}$ & $\mathrm{V}$ & $\mathrm{R}$ & $\mathrm{V}$ \\
\hline 88 & 6.19 & 8.16 & 8.46 & 7.42 & 7.15 & 7.23 & $\mathbf{7 . 1 6}$ & $\mathbf{7 . 1 6}$ & 7.67 & 7.88 \\
\hline 89 & 5.80 & 7.30 & 7.67 & 5.63 & 5.65 & 6.08 & $\mathbf{6 . 3 2}$ & $\mathbf{6 . 3 1}$ & 6.91 & 7.31 \\
\hline 90 & 4.18 & 5.45 & 6.32 & 4.65 & 4.52 & 5.55 & 5.03 & 4.78 & $\mathbf{5 . 8 5}$ & $\mathbf{6 . 1 3}$ \\
\hline 91 & 3.43 & 3.68 & 5.34 & 4.08 & 3.26 & 3.59 & $\mathbf{3 . 7 2}$ & $\mathbf{3 . 7 5}$ & 4.68 & 4.41 \\
\hline 92 & 3.77 & 2.92 & 5.74 & 3.63 & 4.83 & 3.94 & $\mathbf{4 . 2 9}$ & $\mathbf{3 . 8 4}$ & 5.24 & 3.9 \\
\hline 93 & $\mathbf{1 . 9 6}$ & $\mathbf{2 . 2 5}$ & 3.84 & 2.00 & 1.87 & 2.16 & 2.58 & 1.90 & 3.88 & 2.72 \\
\hline 94 & $\mathbf{1 . 2 7}$ & $\mathbf{1 . 3 8}$ & 3.02 & 1.56 & 1.23 & 1.61 & 1.58 & 1.29 & 2.15 & 1.82 \\
\hline 95 & 1.49 & 1.31 & 2.60 & 1.59 & $\mathbf{1 . 8 6}$ & $\mathbf{1 . 8 7}$ & 2.02 & 1.45 & 2.32 & 2.22 \\
\hline
\end{tabular}

Table 3. 3D distance ease $E S_{3 D_{-} \text {waist }}$ values at waist girth: $\mathrm{R}$ - real dress, $\mathrm{V}$ - virtual dress (the best coincidence in each size are marked in bold, while the biggest differences - in Italic)

\begin{tabular}{|c|c|c|c|c|c|c|c|c|c|c|}
\hline \multirow{2}{*}{ Size/Fabric } & \multicolumn{2}{|c|}{02} & \multicolumn{2}{|c|}{03} & \multicolumn{2}{|c|}{04} & \multicolumn{2}{|c|}{05} & \multicolumn{2}{|c|}{06} \\
\hline & $\mathrm{R}$ & V & $\mathrm{R}$ & V & $\mathrm{R}$ & V & $\mathrm{R}$ & V & $\mathrm{R}$ & V \\
\hline 88 & 12.01 & 10.72 & 13.09 & 9.01 & 11.47 & 9.18 & 11.89 & 9.18 & 11.92 & 9.41 \\
\hline 89 & 11.97 & 10.05 & 12.29 & 8.44 & 11.37 & 8.24 & 11.32 & 8.19 & 11.81 & 9.82 \\
\hline 90 & 9.80 & 8.98 & 11.61 & 7.54 & 10.08 & 9.27 & 10.63 & 8.28 & 11.08 & 9.18 \\
\hline 91 & 8.67 & 7.69 & 9.40 & 5.58 & 8.01 & 6.09 & 7.49 & 6.80 & 8.21 & 7.17 \\
\hline 92 & 8.43 & 6.74 & 10.56 & 5.87 & 8.00 & 7.36 & 7.90 & 7.01 & 10.02 & 7.22 \\
\hline 93 & 8.41 & 6.64 & 9.10 & 4.80 & 6.96 & 6.45 & 8.57 & 6.84 & 8.77 & 6.12 \\
\hline 94 & 5.86 & 4.16 & 7.68 & 4.93 & 6.46 & 5.77 & 6.05 & 4.35 & 7.82 & 4.89 \\
\hline 95 & 6.47 & 4.19 & 6.56 & 3.95 & 6.06 & 4.24 & 7.41 & 4.20 & 7.09 & 4.45 \\
\hline
\end{tabular}


Virtual dress with fabric 03 wrinkled in the waist area, while real dress fitted to the body good and no wrinkles were formed. Wrinkles in virtual dress occurred due to the highest shear rigidity $G$ what might not be simulated precisely. There was tendency observed, that by increasing of the mannequin size, the differences between real and virtual dresses at waist girth increased.

Analysing linear relation between mannequin size and 3D distance ease at waist girth of real (Fig. 6) and virtual (Fig. 7) dresses, it was seen that the highest distance ease of real dresses was formed with fabric 03 and 06 , while the highest distance ease of virtual dresses was formed with fabric 02 and 06.

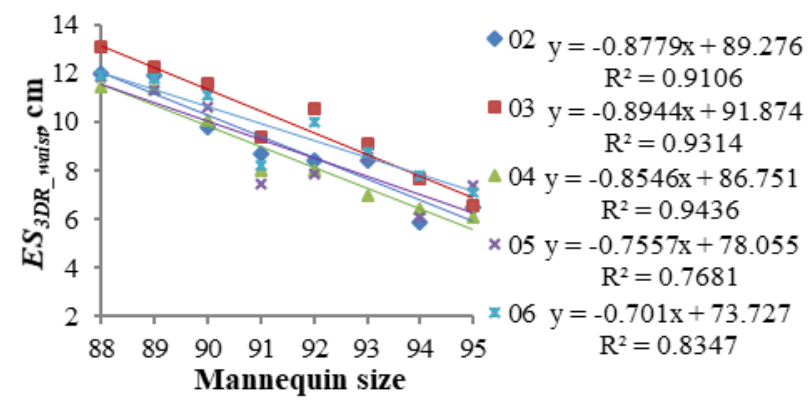

Fig. 6. Linear relations between mannequin size and 3D distance ease of real dress at waist girth

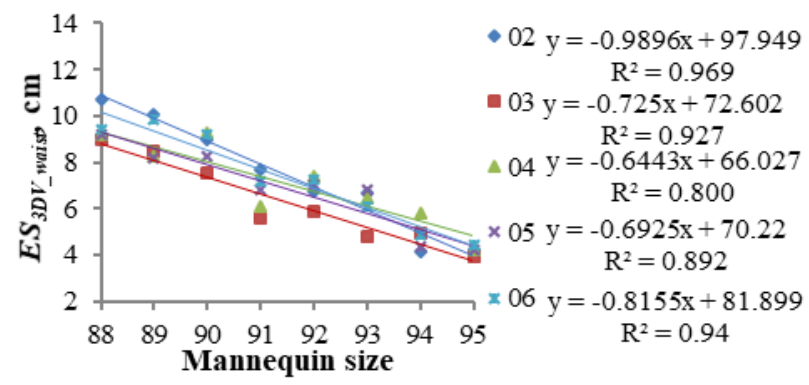

Fig. 7. Linear relations between mannequin size and 3D distance ease of virtual dress at waist girth

It was defined that the position of 3D measure lines at bust and waist girths $L_{3 D_{-} \text {bust,waist }}$ do not match the position of corresponding girths $L_{\text {bust,waist }}$ of mannequin (Fig. 1). This mismatch $h$ was caused by two reasons: fabric deformation which is related to mechanical properties and construction of the garment. Distance ease values strongly depend on the position of $L_{3 D_{-} \text {bust,waist }}$ measure line which can be higher or lower than the girth line $L_{\text {bust.waist }}$ on the mannequin. Due to the undefined bust and waist lines in scanned dress, the position of these lines in real and virtual garments cannot be evaluated, so mismatches $h$ cannot be compared.

Analysing cross-sections of real (Fig. 8 a, Fig. 8 c) and virtual (Fig. 8 b, Fig. 8 d) dresses with different fabrics and 88 size mannequin, it was seen that good fit with the body was obtained in the front side with all fabrics at bust girth, however uneven extra looseness at garment back side was formed. Also wrinkles were formed at left and right sides also back side at waist girth. Size 88 was chosen for the comparison because of the highest values of distance ease.

Differences of cross-section forms of real and virtual dresses at bust and waist girths (Fig. 8) were noted. Crosssections of real and virtual dresses had similar form with all fabrics, especially with 02,05 and 06 at bust and with 04, 05 and 06 at waist girth. High tensile strain EMT values, the lowest bending rigidity $B$, mass per unit area and thickness values of fabric 05 ensured the greatest similarity of cross-section forms. The form of bust and waist cross-sections with fabric 03 had less similarity. The most similar forms were observed at bust in front side and at waist in front left and right sides. Virtual dresses at bust girth had deeper wrinkles in back side and less but deeper wrinkles in both sides. Real dresses at waist girth were tighter in back side than the virtual ones.

It was defined, that by increasing of mannequin size, similarities between real and virtual dresses appearance decreased (Fig. 9). Visual appearance and shape of real and virtual dresses was similar from 88 to 92 mannequin size; wrinkles had similar positions, though directions and forms of them were not identical.

Dresses on 92 size mannequin had the most similar form and position of wrinkles (Fig. 9), while on larger sizes similarities decreased; from 94 size form and position of wrinkles differed more, especially at waist area back side.

Comparing visual appearance of real and virtual dresses with all tested fabrics (Fig. 10), it was seen that fabric 03 had the worst fit because the most wrinkles appeared in the garment due to the highest shear rigidity $G$. Fabric 02 had the best fit to the body (smooth garment shape, few wrinkles) because of the lowest shear rigidity $G$. Virtual dress made of fabric 02 had similar appearance in comparison to corresponding real dress. When shear rigidity had very high value $G>1.60\left(\mathrm{Nm}^{-1} \rho^{\circ}\right)$ in weft direction, virtual dress appearance differed from the real one. So, 3D CAD system could not simulate high $G_{\mathrm{wf}}$ value precisely what could cause less realistic simulation effect.

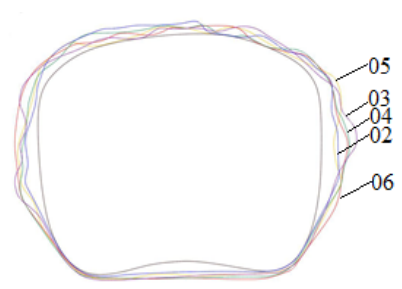

a

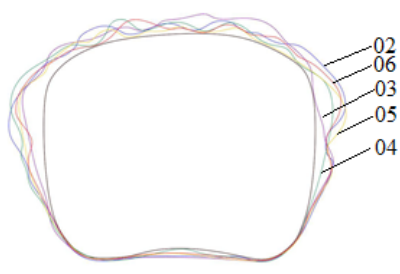

b

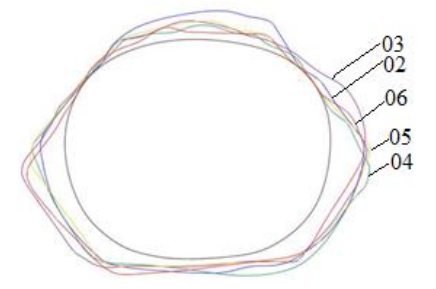

c

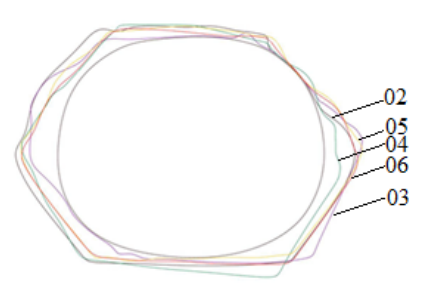

d

Fig. 8. Cross-sections of bust $(a, b)$ and waist $(c, d)$ girths using different fabrics and 88 size mannequin: a/c - real dresses, b/d - virtual dresses 


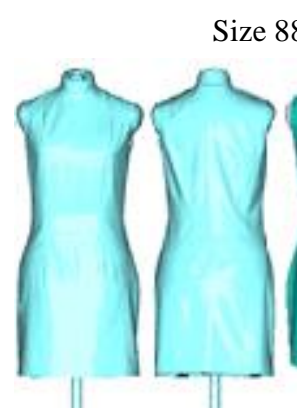

Real dress

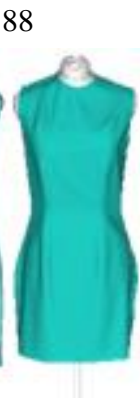

Virtual dres
Size 92

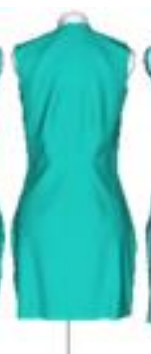

ress

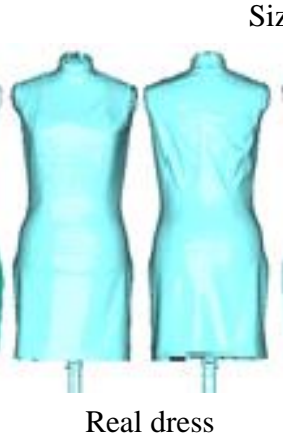

Real dress

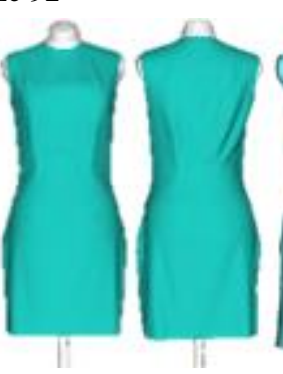

Virtual dress

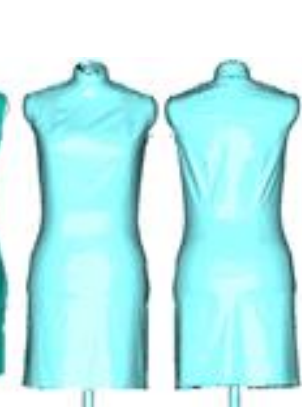

Real dress
Size 95

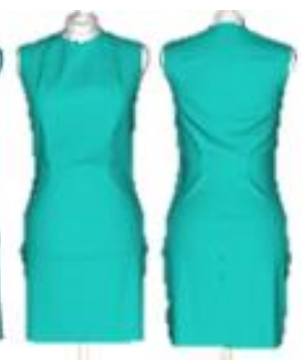

Virtual dress

Fig. 9. Scanned mannequin with real and virtual dresses (fabric 02)
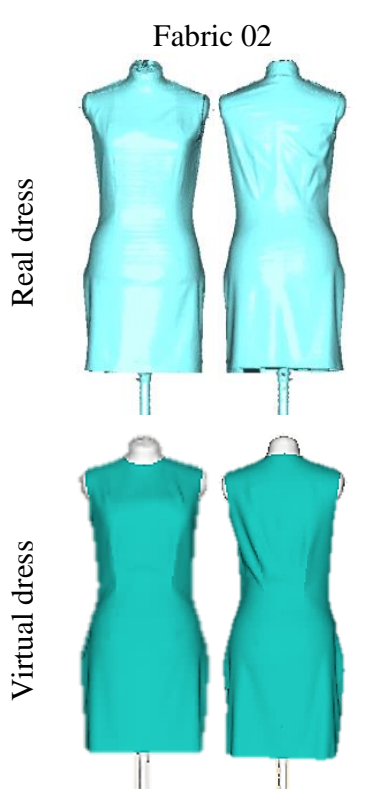

Fabric 03

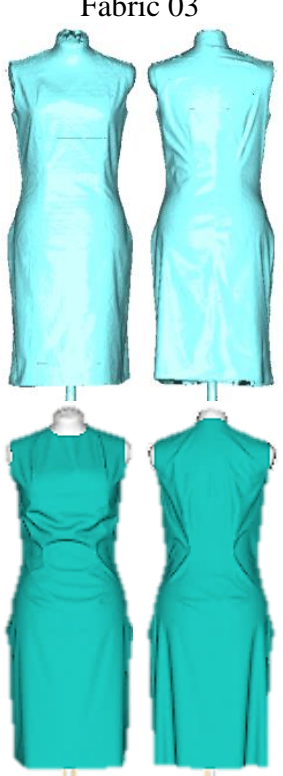

Fabric 04
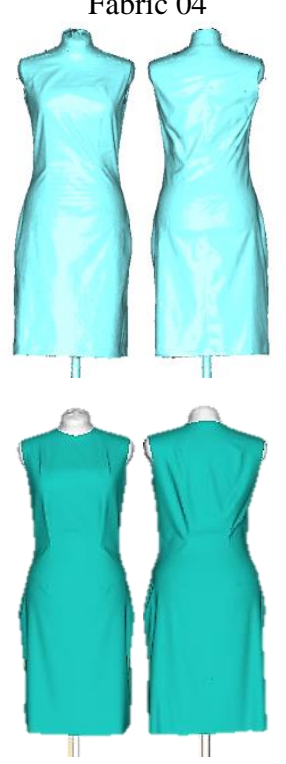

Fabric 05

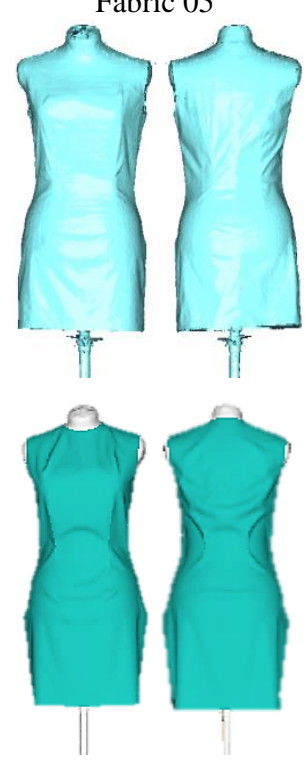

Fabric 06
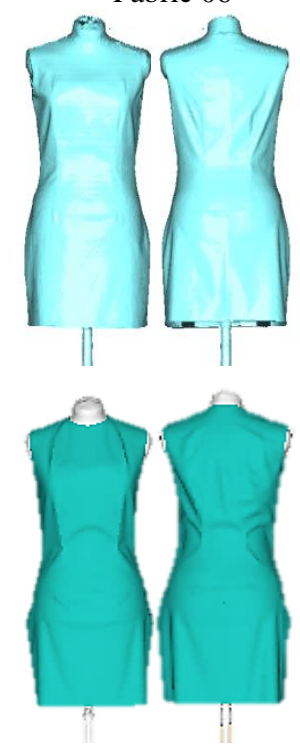

Fig. 10. Scanned mannequin (size 92) with real and virtual dresses using different fabrics

\section{CONCLUSIONS}

The paper concluded that, generally, appearance of the two main cross-sections of the simulated dresses was satisfactory in terms of the real scanned images, but there were some differences in garment shape fluency also in distance ease values between body and garment.

1. The difference of distance ease values between real and virtual dress at bust girth varied up to $29.9 \%$ $(1.16 \mathrm{~cm})$ while analysing without fabric 03 and up to $48.3 \%(1.46 \mathrm{~cm})$ with fabric 03 ;

2. Distance ease values of real and virtual dress at waist girth differed from $7.3 \%(0.51 \mathrm{~cm})$ to $47.3 \%$ $(4.30 \mathrm{~cm})$;

3. Linear relations of real dresses between mannequin size and 3D distance ease values at bust and waist girths showed more clear tendency than of virtual dresses. It was found that the highest distance ease of real dresses at bust and waist girths was formed with fabrics 03 and 06, while of virtual dresses with fabric 06 at bust and with fabric 02 also 06 at waist girths;

4. The most similar appearance, shape also position and form of wrinkles had virtual and scanned dresses on the basic mannequin size of 92 ;

5. Cross-sections of real and virtual dresses had the most similar form with fabric 05 at bust and waist girths due to quite high tensile strain $E M T$ values and the lowest bending rigidity $B$, mass per unit area and thickness values;

6. Fabric 03 had the worst fit, wrinkles occurred due to the highest shear rigidity. It has been assumed that $3 \mathrm{D}$ CAD systems could not reflected very high shear rigidity $G_{w f}>1.60 \mathrm{Nm}^{-1} \rho^{\circ}$ value precisely and it could cause less realistic simulation effect, so higher differences between virtual and real dress view;

7. Results showed that the accuracy of virtual try-on was quite useful comparing to real garments especially for distance ease evaluation at tight-fitting area, but not to the extent that experts could fully use it as a visual fit analysis tool. It is recommended to use for the simulation fabrics with the shear rigidity lower than $1.6 \mathrm{Nm}^{-1} \rho^{\circ}$, tensile strain in warp direction higher than $1.80 \%$ and bending rigidity lower than $5.3 \mathrm{Nm}$.

Values of 3D dress perimeter and distance ease at bust and waist girths depend on the $L_{3 D_{-} \text {bust,waist }}$ measure line position which could be higher or lower than the girth line $L_{\text {bust,waist }}$ on mannequin. It is very complicated task to ensure the same place of girth in the real and virtual dress. So in our future research, we are going to measure the volumetric air gap at the bust and waist girths. This should reduce the mismatch between real and virtual garment distance ease caused by the location of the measuring line. 


\section{REFERENCES}

1. Sayem, A.S.M. Advances in Virtual Prototyping: Opportunities for Clothing Manufacturers Textile Research Conference, 26 December 2015, Dhaka, Bangladesh, TRC Book of Papers 2015: pp. 15-18.

2. Song, H.K., Ashdown, S.P. Investigation of the Validity of 3-D Virtual Fitting for Pants Clothing and Textiles Research Journal 33 (4) 2015: pp. 314-330. https://doi.org/10.1177/0887302X15592472

3. Apeagyei, P.R., Otieno, R. Usability of Pattern Customising Technology in the Achievement and Testing of Fit for Mass Customisation Journal of Fashion Marketing and Management: An International Journal $11(3)$ 2007: pp. 349-365.

https://doi.org/10.1108/13612020710763100

4. Al-Ahmari, A.M., Abidi, M.H., Ahmad, A., Darmoul, S. Development of a Virtual Manufacturing Assembly Simulation System Advances in Mechanical Engineering 8 (3) 2016: pp. 1-13. https://doi.org/10.1177/1687814016639824

5. Yan, J.Q., Zhang, S.C., Kuzmichev, V.E., Adolphe, D.C. New Database for Improving Virtual System "Body-Dress" IOP Conference Series: Materials Science and Engineering 254 (17) 2017: pp. $1-6$. https://doi.org/10.1088/1757-899X/254/17/172029

6. Jevšnik, S., Stjepanovič, Z., Rudolf, A. 3D Virtual Prototyping of Garments: Approaches, Developments and Challenges Journal of Fiber Bioengineering and Informatics 10 (1) 2017: pp. 51-63. https://doi.org/10.3993/jfbim00253

7. Jevšnik, S., Pilar, T., Stjepanovic, Z., Rudolf, A. Virtual Prototyping of Garments and Their Fit to the Body DAAAM International 2012: pp. 601-618.

8. Jevšnik, S., Kalaoğlu, F., Terliksiz, S., Purgaj, J. Review of Computer Models for Fabric Simulation Tekstilec 57 (4) 2014: pp. 300-314. https://doi.org/ 10.14502/Tekstilec2014.57.300-314

9. Liu, K., Zeng, X., Bruniaux, P., Wang, J., Kamalha, E., Tao, X. Fit Evaluation of Virtual Garment Try-on by Learning from Digital Pressure Data Knowledge-Based Systems 133 2017: pp. 174-182. https://doi.org/10.1016/j.knosys.2017.07.0070950 7051

10. Baytar, F., Ashdown, S. An Exploratory Study of Interaction Patterns Around the Use of Virtual Apparel Design and Try-on Technology, Fashion Practice The Journal of Design, Creative Process \& the Fashion Industry 7 (1) 2015: pp. 31-52. https://doi.org /10.2752/175693815X14182200335655

11. Ji, F., Li, R., Qiu, Y. Three-dimensional Garment Simulation Based on a Mass-Spring System Textile Research Journal 76 (1) 2006: pp. $12-17$. https://doi.org /10.1177/0040517506057169

12. Dāboliṇa, I., Vilumsone, A., Dāboliṇš, J., Strazdiene, E., Lapkovska, E. Usability of 3D Anthropometrical Data in CAD/CAM Patterns International Journal of Fashion Design, Technology and Education 10 (1) 2017: pp. $41-52$. https://doi.org /10.1080/17543266.2017.1298848

13. Liu, Y.J, Zhang, D.L., Yuen, M.M.F. A Survey on CAD Methods in 3D Garment Design Computers in Industry 61 2010: pp. 576-593. https://doi.org/10.1016/j.compind.2010.03.007

14. Jevšnik, S., Kalaoğlu, F., Hanife Eryuruk, S., Bizjak, M., Stjepanovič, Z. Evaluation of a Garment Fit Model Using AHP Fibres \& Textiles in Eastern Europe $232(110)$ 2015: pp. $116-122$.

15. Buyukaslan, E., Jevšnik, S., Kalaoglu, F. Virtual Fitting of a Skirt on a Parametric and a Scanned Body Model Marmara Journal of Pure and Applied Sciences Special Issue1 2015: pp. 23-26. https://doi.org /10.7240/mufbed.52347

16. Kuzmichev, V.E., Guo, M. Realistic Virtual System "Female Body - Dress" Based on Scanning Technologies Proceedings 5th International Conference on $3 D$ Body Scanning Technologies (Lugano: Hometrica Consulting) 2014: pp. 196-204. https://doi.org /10.15221/14.196

17. Su, J., Gu, B., Liu, G., Xu, B. Determination of Distance Ease of Pants Using 3D Scanning Data International Journal of Clothing Science and Technology 27 (1) 2015: pp. $47-59$. https://doi.org/10.1108/IJCST-08-2013-0096

18. Gu, B., Su, J., Liu, G., Xu, B. Pattern Alteration of Women's Suits Based on Ease Distribution International Journal of Clothing Science and Technology 28 (2) 2016: pp. $201-215$. https://doi.org/10.1108/IJCST-07-2015-0083

19. Xu, J., Zhang, W., Xiao, P. A Study on Impact Factors of the Distance Eases between Body and Garment Proceedings of Information Conference on Computer-Aided Industrial Design and Conceptual Design 1 2008: pp. $201-205$.

20. Lee, E., Park, H. 3D Virtual Fit Simulation Technology: Strengths and Areas of Improvement for Increased Industry Adoption International Journal of Fashion Design, Technology and Education 10 (1) 2017: pp. 59-70. https://doi.org /10.1080/17543266.2016.1194483

21. Lee, J., Nam, Y., Cui, M., Choi, K., Choi, Y. Fit Evaluation of 3D Virtual Garment; in Usability and Internationalization $\mathrm{HCI}$ and Culture Lecture Notes in Computer Science 4559 2007: pp. 550-558.

22. Lee, J., Lee, J. Comparison on the Pants Fitting for Obese Women between 3D Virtual Garment and Real Garment Journal of Fashion Business 17 (2) 2013: pp. 33-45. http://dx.doi.org/10.12940/jfb.2013.17.2.33

23. Metric Patternmaking for Dresses and Blouses. Patternmaking system M. Müller \& Sohn. Rundschau Publishing, Germany, 2016.

24. Lage, A., Ancutiene, K. Virtual Try-On Technologies in the Clothing Industry. Part 1: Investigation of Distance Ease Between Body and Garment The Journal of the Textile Institute 108 (10) 2017: pp. 1787-1793. https://doi.org / 10.1080/00405000.2017.1286701 